\title{
Performance of a rapid diagnostic test for the detection of visceral leishmaniasis in a large urban setting
}

\author{
Alexandre Sampaio Moura ${ }^{[1],[2], ~ H e l e n ~ M a r i a ~ R a m o s ~ d e ~ O l i v e i r a ~ L o p e s ~}{ }^{[1]}$, \\ Maria Vitória Assumpção Mourão ${ }^{[1]}$ and Maria Helena Franco Morais ${ }^{[1]}$
}

[1] Secretaria Municipal de Saúde, Prefeitura Municipal, Belo Horizonte, MG. [2]. Curso de Medicina, Universidade Federal de Alfenas, Belo Horizonte, MG.

\begin{abstract}
Introduction: Rapid diagnostic tests (RDTs) may improve the early detection of visceral leishmaniasis (VL), but their real-world performance requires additional study. Therefore, we evaluated the performance of an rK39-based RDT (Kalazar Detect ${ }^{\mathrm{TM}}$ ) for the detection of VL in an endemic, large urban area. Methods: Data were collected from a registry of rK39 RDT performed at 11 emergency care units in Belo Horizonte, Brazil, and from a national database of reportable communicable diseases of the Sistema de Informação de Agravos de Notificação (SINAN). Results: The rapid rK39 test was performed in 476 patients, with $114(23.9 \%)$ positive results. The analysis of rK39 RDT performance was based on $381(80 \%)$ cases reported to the SINAN database, of which 145 (38.1\%) were confirmed cases. Estimates for sensitivity and specificity were 72.4\% (95\% CI: 64.6$79 \%$ ) and $99.6 \%$ (95\%CI: 97.6-99.9\%), respectively. Positive and negative predictive values were estimated at $99.1 \%$ (95\%CI: 94.9-99.8\%) and 85.5\% (95\%CI: 80.8-89.1\%), respectively. In addition, close agreement between the rK39 RDT and indirect immunofluorescence was observed. Conclusions: In summary, the rK39 RDT showed a high specificity but only moderate sensitivity. In endemic areas for VL, treatment may be considered in cases with clinical manifestations and a positive rK39 RDT, but those with a negative test should be subjected to further investigation.
\end{abstract}

Keywords: Visceral leishmaniasis. Serologic test. Sensitivity and specificity.

\section{INTRODUCTION}

Visceral leishmaniasis (VL) has a wide global distribution, with 200,000 to 400,000 estimated cases per year ${ }^{1}$, and is the second largest cause of death among parasitic diseases worldwide ${ }^{2}$. Approximately $90 \%$ of cases occur in six countries, including India, Bangladesh, Sudan, South Sudan, Brazil and Ethiopia, with 20,000 to 40,000 estimated deaths per year'. In Brazil, VL is caused by Leishmania (Leishmania) infantum and has been geographically expanding in the past decade ${ }^{3}$. The mean annual incidence for the period 2001-2010 was 1.8/100,000 people, with a case fatality rate of $6.8 \%{ }^{4}$. Belo Horizonte, a city of 2.4 million inhabitants located in the southeastern part of the country, reported a mean incidence of 5.2 cases $/ 100,000$ people during the same time period, with a case fatality rate of $13.4 \%$.

Early diagnosis and treatment of VL have been recommended by the Brazilian National VL Surveillance and Control Program to reduce mortality ${ }^{6}$. According to the Brazilian Ministry of Health, a diagnosis of VL requires the identification of the parasite in a smear or culture and/or positive serological testing in patients presenting with fever and spleen enlargement ${ }^{7}$. The

Address to: Dr. Alexandre Sampaio Moura. Curso de Medicina/UNIFENASBH. Rua Libano 66, Bairro Itapoã, 31710-030 Belo Horizonte, MG, Brasil.

Phone: 5531 3497-4302

e-mail: alexandre.moura@unifenas.br

Received 18 July 2013

Accepted 2 October 2013 most widely available serological test for VL diagnosis in Brazil is indirect immunofluorescence (IFI) ${ }^{6}$; this diagnostic method is typically performed in referral laboratories around the country, and the results become available to the attending physician within a couple of days. As a delay in VL diagnosis may be associated with an increase in case fatality rates ${ }^{8}$, the use of rapid diagnostic tests (RDTs) can help reduce mortality.

The accuracy of immunochromatographic rapid tests based on the rK39 protein of Leishmania infantum has been assessed in studies from different regions ${ }^{2,9}$. The sensitivity of the rK39 RDT has been reported to vary between 37 and $100 \%$, and the specificity was estimated between 59 and $100 \%$ among immunocompetent patients in endemic regions ${ }^{9-16}$. In addition, a meta-analysis of 13 studies reported an overall sensitivity and specificity of $93.9 \%$ and $90.6 \%$, respectively ${ }^{15}$. In Brazil, estimates of the sensitivity and specificity of RDTs vary between 85.7 and $100 \%$ and 82.0 and $100 \%$, respectively ${ }^{17-21}$, but few studies have been conducted in real-world scenarios. For example, among immunocompromised patients, the sensitivity of RDTs seems to be lower, with one study reporting an estimation of $77.3 \%{ }^{16}$. Moreover, in a previous Brazilian study, the performance of the rK39 RDT was inferior to the use of a parasitological method, real-time PCR in peripheral blood and a prototype kit for a direct agglutination test (DAT) among human immunodeficiency virus (HIV)-positive patients ${ }^{22}$.

In Belo Horizonte, the rK39 RDT was implemented at emergency care units in 2010 to foster the early treatment of suspected VL cases with a positive test, according to World Health Organization (WHO) recommendations ${ }^{23}$. The objective of the present study was to assess rK39 RDT performance in widespread use in a large urban area with a high incidence of VL. 


\section{METHODS}

An RDT for VL was implemented in Belo Horizonte in May 2010 at 11 public emergency care units. This RDT provided by the Ministry of Health was marketed as Kalazar Detect ${ }^{\mathrm{TM}}$ (InBios International), an immunochromatographic test that provides the qualitative detection of antibodies against the recombinant K39 (rK39) protein of Leishmania.

The use of the rK39 RDT was recommended in Belo Horizonte for the following situations: patients of any age with I) fever of any duration with spleen enlargement or II) fever lasting 14 or more days associated with any cytopenia (anemia, leukopenia or low platelet counts). Serum samples were obtained immediately after consultation, and a trained health professional performed the RDT at the point-of-care. A sample of serum was sent to Fundação Ezequiel Dias (FUNED), a national referral laboratory, which blindly performed indirect immunofluorescence (IFI) assays for $\mathrm{VL}$; this method is considered the standard serological test in Brazil. According to the recommendations from the Ministry of Health, the reporting of all suspected VL cases to a public health authority is mandatory, and data are recorded at a national database of reportable communicable diseases (SINAN). This study included all patients who received the rK39 RDT at one of the 11 public emergency care units of Belo Horizonte from May 2010 to July 2011 and had SINAN data available. Clinical and demographic information was obtained from the SINAN database. The RDT results were obtained from spreadsheets that were regularly filled out by the laboratory manager of each of the healthcare units, and the IFI results were obtained directly from the FUNED lab. Indirect immunofluorescence results were considered as reactive when the titers were equal or greater than 1:80.
The following Ministry of Health definition of a confirmed VL case was used to assess RDT performance: individuals from an area of occurrence of VL with fever and spleen enlargement I) in whom the parasite is identified in direct examination or culture and/or II) demonstrate a positive IFI reaction (titer equal or greater than 1:80) or, although not showing laboratory confirmation, III) demonstrate a favorable treatment response. Notably, all confirmed cases were followed by the city health department's epidemiological bureau to assess patient's outcomes, particularly their response to treatment.

To assess the performance of the RDT among HIV patients, information on HIV serology was obtained from the SINAN database.

Statistical analyses were conducted using OpenEpi (Open Source Epidemiologic Statistics for Public Health, Version 2.3.1).

\section{Ethical considerations}

The study was approved by the ethics committee at the Belo Horizonte Health Department and was performed in accordance with the ethical standards of the Declaration of Helsinki.

\section{RESULTS}

The rapid diagnostic test for VL was performed in 476 patients throughout the study period. Among these patients, 381 $(80 \%)$ had SINAN data available and were included in the study. There was a predominance of male patients $(68.8 \%)$, with a mean age of 28 years (7-88 years) (Table 1). According to the Ministry of Health case definition, 145 (38.1\%) patients had confirmed VL, with $28(19.3 \%)$ cases meeting the parasitological criteria, $112(77.2 \%)$ meeting the serological (IFI) criteria

TABLE 1 - Demographic and clinical characteristics of 381 patients that performed rK39 rapid diagnostic test for diagnosis of visceral leishmaniasis.

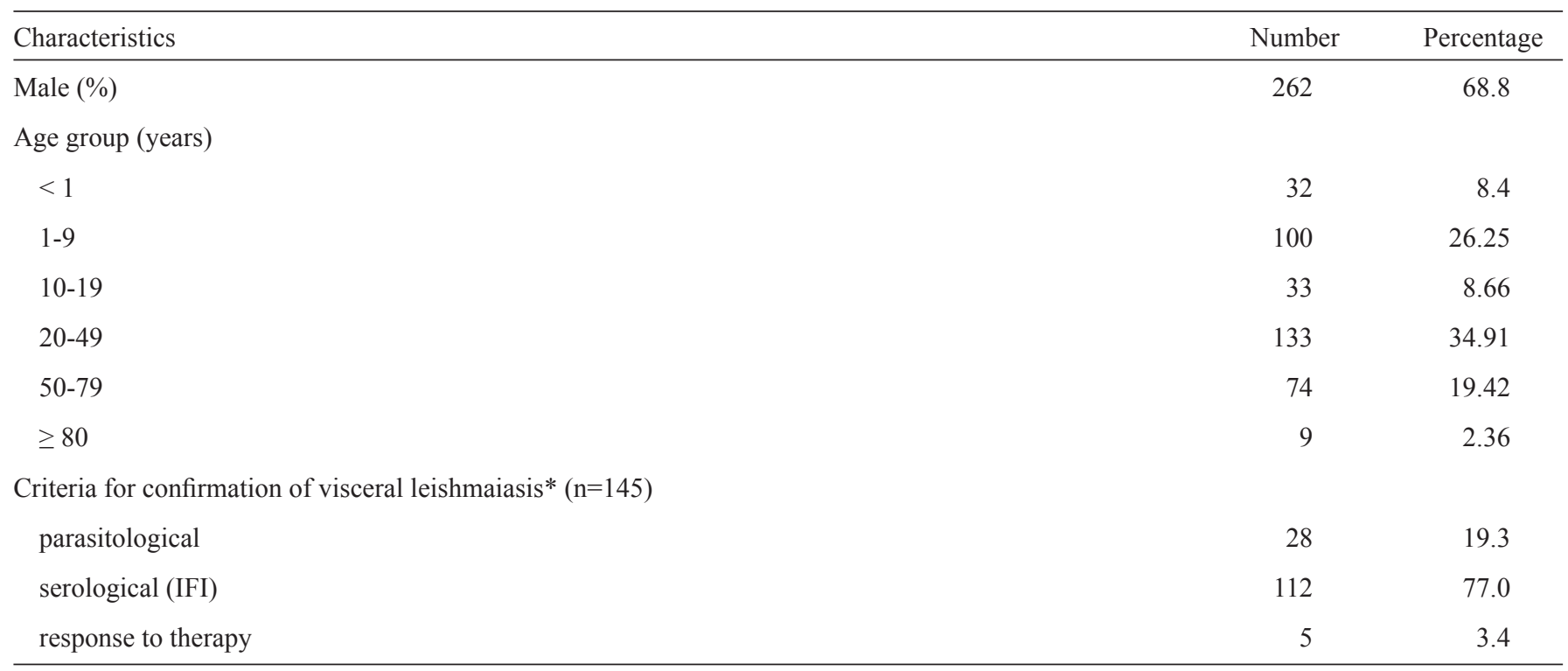

*Confirmation criteria was ranked in the following order: parasitological, serological and response to therapy. IFI: indirect immunofluorescence for detection of Leishmania antibodies; rK39: recombinant K39. 
and $5(3.4 \%)$ demonstrating a favorable treatment response without positive results in parasitological or serological tests.

Among the 145 confirmed VL cases, 105 had a positive RDT, and among the 236 non-confirmed cases, 235 had had a negative RDT. The sensitivity and specificity of rK39 RDT were estimated at $72.4 \%$ (95\%CI: $64.6-79 \%$ ) and $99.6 \%$ (95\%CI: 97.6-99.9\%), respectively (Table 2). Estimates for the positive (PPV) and negative (NPV) predictive values were 99.1\% (95\%CI: $94.8-99.8 \%$ ) and $85.5 \%$ (95\%CI: $80.8-89.1 \%$ ), respectively. Because information on the final diagnosis was not available for 95 of the 476 patients who received the RDT, we conducted a sensitivity analysis including all patients for whom we had RDT results available. For this analysis, we considered two hypothetical extreme situations to address the missing data for a final diagnosis: I) all 95 patients with missing data had visceral leishmaniasis or II) all of these patients did not have VL. Considering the first scenario, the estimates for sensitivity, specificity, PPV and NPV were $47.1 \%$ (95\%CI: 40.9-50.4\%), 99.6\% (95\%CI: 97.6-99.9\%), 99.1\% (95\%CI: $95.2-99.8 \%$ ) and $64.9 \%$ (95\%CI: 59.9-69.6\%), respectively. For the latter situation, the estimates for the same parameters were $72.4 \%$ (95\%CI: $64.3-79 \%$ ), 97.3\% (95\% CI: 94.9-98.6\%), 92.1\% (95\%CI: 85.7-95.8\%) and 88.9\% (95\% CI: 85.3-91.8\%), respectively.

Among the 28 patients with amastigotes detected in bone marrow aspirates, the rK39 RDT was positive in 17 (60.7\%) cases. Of note, $14(50 \%)$ of these 28 patients were HIV-positive.

Information on HIV co-infection was available for 224 of the 381 included patients, and 93 of these patients were found to be HIV-positive. Among HIV-infected patients, the sensitivity and specificity of the RDT were estimated at $60 \%(95 \% \mathrm{CI}$ : $40.7-76.6 \%)$ and $100 \%(95 \% \mathrm{CI}: 94.7-100 \%)$, respectively. The positive and negative predictive values for this subset of patients were estimated at $100 \%(95 \% \mathrm{CI}: 79.6-100 \%)$ and $87.2 \%(95 \%$ CI: 77.9-92.9\%), respectively.

Information on the results of indirect immunofluorescence was available for 296 of the 381 included patients. A reactive IFI result was observed in $63(86.3 \%)$ of the 73 samples that had previously been shown to be positive in the rK39 RDT, and $200(89.6 \%)$ of the 223 samples from patients with a negative result on the RDT were also negative for IFI (Table 3).

TABLE 2 - Evaluation of rK39 rapid diagnostic test performance for diagnosis of visceral leishmaniasis.

\begin{tabular}{lccc}
\hline & \multicolumn{3}{c}{ Cases } \\
\cline { 2 - 4 } RDT & 105 & 1 & Total \\
\hline Positive & 40 & 235 & 106 \\
Negative & 145 & 236 & 381 \\
\hline Total & & not confirmed & \\
\hline
\end{tabular}

RDT: rapid diagnostic test; ${ }^{a}$ confirmed according to Brazilian Ministry of Health criteria; rK39: recombinant K39.
TABLE 3 - Analysis of agreement between rK39 rapid diagnostic test and indirect immunofluorescence for the diagnosis of visceral leishmaniasis.

\begin{tabular}{lccc}
\hline & \multicolumn{3}{c}{ Indirect immunofluorescence } \\
\cline { 2 - 4 } RDT & $\geq 1: 80$ & $<1: 80$ & total \\
\hline Positive & 63 & 10 & 73 \\
Negative & 23 & 200 & 223 \\
\hline Total & 86 & 210 & 296 \\
\hline
\end{tabular}

RDT: rapid diagnostic test. Kappa 0.71 (CI95\% 0.60-0.83). rK39: recombinant K39; CI: confidence interval.

\section{DISCUSSION}

Rapid diagnostic tests (RDTs) based on rK39 showed good accuracy for VL diagnosis when widely implemented in a large urban area. Moreover, the high PPV estimates support the World Health Organization ${ }^{23}$ and the Brazilian Ministry of Health ${ }^{7}$ recommendations for the use of RDTs to confirm a VL diagnosis in suspected cases. However, due to the moderate estimates for NPV, our findings suggest that patients with negative RDT results should undergo further investigation with additional serological tests and examination of bone marrow aspirates. Polymerase chain reaction for the detection of Leishmania deoxyribonucleic acid (DNA) in bone marrow or peripheral blood specimens might also be useful to confirm or rule out VL diagnosis in challenging situations $\mathrm{s}^{23-26}$.

An evaluation of rK39 RDT performance revealed better results for studies conducted in the Indian subcontinent as compared to those from East Africa or Brazil ${ }^{9}$. Differences in study design, the species of Leishmania responsible for $\mathrm{VL}$ cases and antibody concentrations might explain this variation in RDT performance. An initial evaluation of the performance of the rK39 RDT in India estimated its sensitivity and specificity at $100 \%$ and $98 \%$, respectively ${ }^{11}$. Of note, this previous study considered confirmed VL cases to be only those with parasitological confirmation. A controlled study subsequently conducted in India by the same research group, which sought to validate another type of rK39 RDT (One Step Insure ${ }^{\mathrm{TM}}$ ), reported a sensitivity of $100 \%$ and a specificity of $93 \%$ using the same case criteria as their previous study ${ }^{27}$.

In Uganda, Kalazar Detect ${ }^{\mathrm{TM}}$ was used for the diagnosis of VL among 250 inpatients admitted with a clinical presentation compatible with $\mathrm{VL}^{28}$, and this RDT demonstrated good accuracy, with a sensitivity and specificity estimated at $82 \%$ and $99 \%$, respectively. It is interesting to note that this Uganda study used confirmation criteria that included the detection of the parasite in a spleen aspirate smear, a positive direct agglutination test (i.e., titers greater than 1:12,800) or a good treatment response.

In a study conducted in Sudan using a different rK39 RDT (IT-LEISH ${ }^{\mathrm{TM}}$ ) but also including a serological test (direct agglutination test) among the confirmation criteria for VL cases, 
similar results were found for sensitivity, specificity, PPV and NPV $(81 \%, 97 \%, 98 \% \text { and } 71 \% \text {, respectively })^{10}$.

In Brazil, validation studies of the IT-LEISH ${ }^{\mathrm{TM}}$ have reported a sensitivity varying from $93 \%$ to $100 \%$ and a specificity between $94 \%$ and $96 \%{ }^{18,20}$, considering confirmed cases only as those with a parasitological diagnosis. In addition, the PPV and NPV of $98 \%$ and $89 \%$, respectively, were similar to those found in our study. Evaluations of the performance of Kalazar Detect $^{\mathrm{TM}}$ have shown sensitivity values between $85.7 \%$ and $90 \%$ and a specificity between $82 \%$ and $100 \%^{18,19}$.

In a multicentric study, four commercially available RDTs were compared, including Kalazar Detect ${ }^{\mathrm{TM}}$. Both at Brazilian and African centers, Kalazar Detect ${ }^{\mathrm{TM}}$ presented a lower sensitivity when compared to IT-LEISH ${ }^{\mathrm{TM}}$, which must be taken into account when using these tests in clinical practice?

Our study also found that the sensitivity of the RDT seemed to be lower among HIV-infected patients compared to the general population. However, we had no information regarding the cluster of differentiation 4 (CD4)-T cell counts or HIV staging of these patients with which to establish the impact of immunosuppression on test performance. In addition, we were unable to find any studies in the literature designed specifically to address rK39 RDT accuracy among HIV-infected patients. A study in Ethiopia, a country with a high HIV prevalence, reported an RDT sensitivity of $77 \%$ for HIV-positive patients, which was lower than that observed for HIV-negative patients (87\%), but this difference was not statistically significant ${ }^{15}$. In addition, a recent meta-analysis of diagnostics tests for VL in HIV-infected patients did not include the rK39 RDT due to the lack of previously published studies ${ }^{29}$.

Finally, we found a close agreement between the RDT and the frequently used IFI test. A similar finding was observed in a study comparing an RDT with the direct agglutination test (DAT) ${ }^{30}$. Nonetheless, a Brazilian study showed that ITLEISH $^{\mathrm{TM}}$, but not Kalazar Detect ${ }^{\mathrm{TM}}$, performed significantly better than IFI with greater specificity and $\mathrm{PPV}^{21}$. This finding suggests that RDTs may be an effective substitute for IFI in most clinical situations, considering their rapid results and ease of use.

One limitation of our study involves the criteria used to confirm VL cases. We chose to use the Brazilian Ministry of Health criteria and therefore considered confirmed cases as not only those with parasitological diagnosis but also those with a reactive IFI and/or good treatment response. In our view, the use of the Ministry of Health criteria better reflects the real-world scenario of clinical practice. In addition, because we did not have information on the final diagnosis of the non-confirmed cases, interpretations of the estimates regarding specificity should consider this limitation. Finally, the clinical and demographic data were obtained from the SINAN database, and although reporting is mandatory, the attending physicians do not always report suspected cases. As a result, we were unable to obtain these data for approximately $20 \%$ of the cases. To address this gap, we performed a sensitivity analysis considering two extreme situations, and these results indicated that this lack of data did not change our main finding of the low sensitivity and good specificity of the rK39 RDT.
In summary, the rK39 RDT showed good accuracy for VL diagnosis and close agreement with IFI and may therefore be useful for the timely identification of cases in point-of-care treatment. However, this test is not sufficient to rule out VL, and further testing is warranted in suspected cases with negative RDT results.

\section{CONFLICT OF INTEREST}

The authors declare that there is no conflict of interest.

\section{REFERENCES}

1. Alvar J, Vélez ID, Bern C, Herrero M, Desjeux P, Cano J, et al. Leishmaniasis worldwide and global estimates of its incidence. PLoS ONE 2012; 7:e35671.

2. Chappuis F, Sundar S, Hailu A, Ghalib H, Rijal S, Peeling RW, et al. Visceral leishmaniasis: what are the needs for diagnosis, treatment and control? Nat Rev Microbiol 2007; 5:873-882.

3. Gontijo CMF, Melo MN. Leishmaniose visceral no Brasil: quadro atual, desafios e perspectivas. Rev Bras Epidemiol 2004; 7:338-349.

4. Ministério da Saúde. Secretaria de Vigilância em Saúde. Letalidade de leishmaniose visceral. Brasil, Grandes Regiões e Unidades Federadas, 2000-2010 [Internet]. Brasília: Ministério da Saúde [cited 2013 Jul 13]. Available at: portal.saude.gov.br/ portal/arquivos/pdf/lv_letalidade_05_09_11.pdf

5. Prefeitura de Belo Horizonte. Vigilância Epidemiológica da Leishmaniose Visceral em BH [Internet]. Belo Horizonte: Prefeitura de Belo Horizonte [cited 2013 Jul 13]. Available at: http://portalpbh.pbh.gov.br/pbh/ecp/ comunidade.do? evento=portlet\&pIdPlc=ecpTaxonomiaMenuPortal\&app $=$ s.aude \&tax $=22301 \&$ lang $=p t \_B R \& p g=5571 \& \operatorname{taxp}=0 \& /$.

6. Ministério da Saúde. Secretaria de Vigilância em Saúde. Manual de Vigilância e Controle da Leishmaniose Visceral. Brasília; 2006. 120 p.

7. Ministério da Saúde. Secretaria de Vigilância em Saúde. Leishmaniose Visceral - Recomendações para Redução da Letalidade. Brasília; 2011.

8. Oliveira JM, Fernandes AC, Dorval MC, Alves TP, Fernandes TD, Oshiro ET, Oliveira AL. Mortalidade por leishmaniose visceral: aspectos clínicos e laboratoriais. Rev Soc Bras Med Trop 2010; 43:188-193.

9. Cunningham J, Hasker E, Das P, El Safi S, Goto H, Mondal D, et al. A global comparative evaluation of commercial immunochromatographic rapid diagnostic tests for visceral leishmaniasis. Clin Infect Dis 2012; 55:1312-1319

10. Ritmeijer K, Melaku Y, Mueller M, Kipngetich S, O'Keeffe C, Davidson RN. Evaluation of a new recombinant k39 rapid diagnostic test for Sudanese visceral leishmaniasis. Am J Trop Med Hyg 2006; 74:76-80.

11. Sundar S, Reed SG, Singh VP, Kumar PC, Murray HW. Rapid accurate field diagnosis of Indian visceral leishmaniasis. Lancet 1998; 351:563-565.

12. Zijlstra EE, Nur Y, Desjeux P, Khalil EAG, El-Hassan AM, Groen J. Diagnosing visceral leisimaniasis with the recombinant K39 strip test: experience from Sudan. Trop Med Int Health 2001; 6:108-113.

13. Veeken H, Ritmeijer K, Seaman J, Davidson R. Comparison of an rK39 dipstick rapid test with direct agglutination test and splenic aspiration for the diagnosis of kala-azar in Sudan. Trop Med Int Health 2003; 8:164-167.

14. Terán-Ángel G, Rodríguez V, Silva R, Zerpa O, Schallig H, Ulrich M, Cabrera M. Herramientas no invasivas en Venezuela: comparación entre las pruebas inmunoserológicas DAT, rK26 y rK39 en el diagnóstico de leishmaniasis visceral. Biomedica 2010; 30:39-45.

15. Chappuis F, Rijal S, Soto A, Menten J, Boelaert M. A meta-analysis of the diagnostic performance of the direct agglutination test and rK39 dipstick for visceral leishmaniasis. BMJ 2006; 333:723.

16. Horst R, Tefera T, Assefa G, Ebrahim AZ, Davidson RN, Ritmeijer K. Field evaluation of rK39 test and direct agglutination test for diagnosis 
of visceral leishmaniasis in a population with high prevalence of human immunodeficiency virus in Ethiopia. Am J Trop Med Hyg 2009; 80: 929-934.

17. Assis TSM, Braga ASC, Pedras MJ, Oliveira E, Barral A, Siqueira IC, et al. Multi-centric prospective evaluation of rk39 rapid test and direct agglutination test for the diagnosis of visceral leishmaniasis in Brazil. Trans R Soc Trop Med Hyg 2011; 105:81-85.

18. Schallig HDFH, Canto-Cavalheiro M, Silva ES. Evaluation of the direct agglutination test and the rK39 dipstick test for the sero-diagnosis of visceral leishmaniasis. Mem Inst Oswaldo Cruz 2002; 97:1015-1018.

19. Carvalho SFG, Lemos EM, Corey R, Dietze R. Performance of recombinant K39 antigen in the diagnosis of Brazilian visceral leishmaniasis. Am J Trop Med Hyg 2003; 68:321-324.

20. Amato Neto V, Amato VS, Tuon FF, Gakiya E, Marchi CR, Souza RM, et al. False-positive results of a rapid K39-based strip test and Chagas disease. Int J Infet Dis 2009; 13:182-185.

21. Peruhype-Magalhães V, Machado-de-Assis TS, Rabello A. Use of the Kala-Azar Detect $₫$ and IT-LEISH ${ }^{\circledR}$ rapid tests for the diagnosis of visceral leishmaniasis in Brazil. Mem Inst Oswaldo Cruz 2012; 107: 951-952.

22. Cota GF, Sousa MR, Freitas Nogueira BM, Gomes LI, Oliveira E, Assis TS, et al. Comparison of parasitological, serological, and molecular tests for visceral leishmaniasis in HIV-infected patients: a cross-sectional delayed-type study. Am J Trop Med Hyg 2013; 89:570-577.

23. World Health Organization. Visceral Leishmaniasis Rapid Diagnostic Test Performance [Internet]. Geneva: World Health Organization. Diagnostics Evaluation Series No 4. [cited $2013 \mathrm{Jul}$ 13]; Available at http://www.who. int/tdr/publications/tdr-research-publications/vl-rdt-evaluation/en/
24. Cascio A, Calattini S, Colomba C, Scalamogna C, Galazzi M, Pizzuto $\mathrm{M}$, et al. Polymerase chain reaction in the diagnosis and prognosis of Mediterranean visceral leishmaniasis in immunocompetent children. Pediatrics 2002; 109:e27.

25. Antinori S, Calattini S, Longui E, Bestetti G, Piolini R, Magni C, et al. Clinical use of polymerase chain reaction performed on peripheral blood and bone marrow samples for the diagnosis and monitoring of visceral leishmaniasis in HIV-infected and HIV-uninfected patients: a singlecenter, 8-year experience in Italy and review of the literature. Clin Infect Dis 2007; 44:1602-1610.

26. Fraga TL, Brustoloni YM, Lima RB, Dorval EC, Oshiro ET, Oliveira $\mathrm{J}$, et al. Polymerase chain reaction of peripheral blood as a tool for the diagnosis of visceral leishmaniasis in children. Mem Inst Oswaldo Cruz 2010; 105:310-313.

27. Sundar S, Pai K, Sahu M, Kumar V, Murray HW. Immunochromatographic strip-test detection of anti-K39 antibody in Indian visceral leishmaniasis. Ann Trop Med Parasitol 2002; 96:19-23.

28. Chappuis F, Mueller Y, Nguimfack A, Rwakimari JB, Couffignal S, Boelaert M, et al. Diagnostic accuracy of two rK39 antigen-based dipsticks and the formol gel test for rapid diagnosis of visceral leishmaniasis in northeastern Uganda. J Clin Microbiol 2005; 43:5973-5977.

29. Cota GF, Sousa MR, Demarqui FN, Rabello A. The diagnostic accuracy of serologic and molecular methods for detecting visceral leishmaniasis in HIV infected patients: meta-analysis. PLoS Negl Trop Dis 2012; 6:e1665.

30. Bern C, Jha SN, Joshi AB, Thakur GD, Bista MB. Use of the recombinant K39 dipstick test and the direct agglutination test in a setting endemic for visceral leishmaniasis in Nepal. Am J Trop Med Hyg 2000; 63:153-157. 